\title{
Interação e satisfação de trabalhadores da base fabril no Facebook
}

Interaction and satisfaction of factory workers in Facebook

Interacción y satisfacción de los trabajadores de las fábricas de Facebook

Maria Lúcia Salgueiro dos Santos

Mestre em Comunicação pela Universidade Federal do Paraná (UFPR)

- Graduada em Jornalismo pela Universidade Federal de Santa Catarina (UFSC)

- Membro do grupo de pesquisa "Comunicação para o Século XXI" (COMXXI)

- Consultora independente de Comunicação Corporativa

- E-mail: salgueiro.malu@gmail.com

(9) Claudia Irene de Quadros

- Pesquisadora de pós-doutorado em Comunicação pela Universidade Pompeu Fabra

- Doutora em Comunicação pela Universidade de La Laguna

- $\quad$ Pós-graduação em Comunicação pela UFPR

- Graduada em Comunicação Social pela UFPR

- Coordenadora do grupo de trabalho "Estudos de Jornalismo" da Compós (2018-2020)

- Coordenadora do grupo de pesquisa COMXXI

- E-mail: clauquadros@gmail.com 
Resumo

Este estudo investiga relações entre interações digitais na comunicação interna informal e satisfação de empregados da base industrial brasileira de uma fábrica de eletrodomésticos multinacional. 0 Facebook é analisado por ser um dos dispositivos mais utilizados pelos profissionais em tela. Além da observação silenciosa da página criada de forma independente por esses empregados, realizamos análise de conteúdo, análise documental da organização e entrevistas. Os fundamentos da etnografia destacaram o senso de colaboração, de identidade e de pertencimento dos funcionários.

PALAVRAS-CHAVE: COMUNICAÇÃO ORGANIZACIONAL • MÍDIAS SOCIAIS • INTERAÇÕES • SATISFAÇÃO LABORAL.

Abstract

This study investigates the relationship between digital interactions in informal internal communication and employee satisfaction of the Brazilian industrial base of a multinational appliance factory. Facebook is analyzed for being one of the most used devices by those professionals. In addition to the silent observation of the fanpage created independently by these employees, we performed content analysis, documentary analysis of the organization, and interviews. The foundations of ethnography highlighted the spirit of collaboration, identity and belonging of the employees.

KEYWORDS: ORGANIZATIONAL COMMUNICATION • SOCIAL MEDIA •INTERACTIONS • JOB SATISFACTION.

\section{Resumen}

Este estudio investiga las relaciones entre interacciones digitales en la comunicación interna informal y de satisfacción de trabajadores de la base industrial brasileña en una fábrica de electrodomésticos multinacional. El Facebook es analizado por ser uno de los dispositivos más utilizados por esos profesionales. Además de la observación silenciosa de la página creada de forma independiente por estos empleados, hicimos el análisis de contenido, el análisis documental de la organización y las entrevistas. Los fundamentos de la etnografía resaltan el sentido de colaboración, de identidad y de pertenencia de los empleados. 


\section{INTRODUÇÃO}

\section{Interações em rede e a comunicação interna}

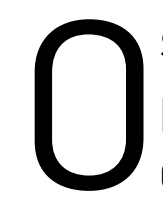

senso de colaboração, de identidade e de pertencimento encontrados entre os funcionários que fizeram parte desta pesquisa integram um miximportante para ampliar o significado do trabalho e incrementar a cultura organizacional que depende de equipes satisfeitas para sua sustentação. Neste artigo, buscamos mostrar como a sociedade em rede tem contribuído para ampliar essas interações que também permitem promover a satisfação no trabalho.

Afinal, as interações integram fluxos cada vez mais intensos na dinâmica social de um para muitos, gerando o que Manuel Castells (2015) conceitua como comunicação individual de massas. À medida que as pessoas se apropriam de inovadoras plataformas abertas de comunicação, elas constroem seus próprios espaços comunicativos, tornando-se produtores independentes de conteúdo e consequentemente influenciadores de opinião. Para o autor, isso potencializa a atual revolução social da sociedade midiatizada hiperconectada: "Os usos da internet aumentam a sociabilidade e o empoderamento, dois fatores críticos que induzem as pessoas à satisfação em suas vidas" (CASTELLS, 2015, p.39).

Autores da perspectiva interpretativa escolhida como matriz teórica para esta pesquisa (Casali, 2009; Kunsch, 2009; Taylor; Every, 2000) classificam a comunicação como metáfora organizacional, ou seja, aquilo que a representa em sua essência. "As organizações resultam das práticas cotidianas de seus membros, compreendendo-as como sistemas de indivíduos em interações" (Casali, 2009, p. 113). E a comunicação interna, foco deste trabalho, sofreu diversas transformações com 0 desenvolvimento da convergência tecnológica, cultural e profissional.

As organizações têm reconhecido a importância estratégica da comunicação interna para o desenvolvimento das instituições, superando uma visão funcionalista que surgiu há sete décadas, quando começou a ser desenvolvida no Brasil. Boa parte dessa nova visão está relacionada ao crescimento das relações virtuais, mais fluidas e dispersas. Entre os autores que se debruçam sobre esse fenômeno, estão Corrêa (2009), Marchiori (2011), Bueno (2015), Terra (2015), Carramenha (2017), Dreyer (2017) e Soares e Del Gáudio (2017).

Marchiori (2011) define como modelo transacional a comunicação contemporânea em que as pessoas exercem todos os papéis ao mesmo tempo, numa relação de negociação intercambiada entre sujeitos, hierarquias e comunidades. Ou seja, fala-se "para" e "com" muitos e ainda com "um", tudo em paralelo, off-line e on-line com ausência de localidades e temporalidades. Tal complexidade pode ser interpretada pelo novo contexto cultural que implica não só polifonia (múltiplas vozes), mas também polissemia (múltiplos sentidos) e, muitas vezes, em cacofonia (convivência não harmônica de vozes diversas).

Logo, a comunicação interna deixa de centralizar a gestão nos meios de comunicação para incentivar modelos transacionais, descentralizados e cocriados por agentes envolvidos neste processo radial. A experiência do Facebook - um dos principais artefatos da sociedade em rede e da comunicação individual em massa - traduz essa perspectiva transacional da comunicação que potencializa a interatividade.

Para Primo (2007, p.40), a interatividade é "um espaço de manipulação por parte do receptor que se transforma em coautor". A interatividade, que pode ocorrer em diferentes níveis, possibilita o diálogo e a participação. Neste artigo, verificamos como se dá a interação do funcionário da base industrial que participa da página da fábrica criada pelos próprios empregados no 
Facebook. Por isso, interessa-nos a interação individual com o dispositivo' e a interpessoal. Segundo Recuero (2009), o exame do ciberespaço traz pistas únicas para o estudo social das redes, como estruturas interativas, capital relacional, emergência da cooperação e da competição, entre inúmeras outras possibilidades de identificação e análise das forças que movem a sociedade. Para a autora, em princípio, uma rede social digital é formada quando pessoas estão conectadas por meio de uma rede de computadores.

Mas Recuero reconceitua a interatividade pela composição básica de dois elementos que não podem ser tratados isoladamente: atores (os nós da rede) e conexões (os laços sociais): "as redes sociais na internet são constituídas de representações dos atores sociais e de suas conexões" (Recuero, 2009, p.38). Essa abordagem resgata a mesma linha proposta por Braga (2012): pessoas em relação. 0 que muda é o meio em que se dá o relacionamento. Só que este não é um mero detalhe tecnológico, pois carrega um fator cultural que traz uma importante mudança nas relações sociais a partir do que se convencionou chamar de comunidades virtuais. Estas seriam resultado de adaptação entre caos e ordem social, fruto de trocas simbólicas. Conforme Recuero (2009, p.144), "comunidade virtual é um conjunto de atores e suas relações, que através da interação em um determinado espaço constitui laços em uma estrutura de cluster, através do tempo, associado a um tipo de pertencimento". Ao partir dessa perspectiva, compreendemos a rede social como o espaço em que determinada comunidade se organiza virtualmente pelo senso de afiliação ou pertencimento, com implicações diretas na satisfação com o trabalho.

\section{REFERENCIAL TEÓRICO}

\section{Interações digitais e satisfação laboral}

0 uso das mídias sociais digitais nos ambientes corporativos tem sido objeto de inúmeros estudos (Barichello; Scheid, 2017; Bueno, 2013; Carramenha, 2017; Carvalho; Fort, 2017; Corrêa, 2009; Di Felice, 2007; Lupianhes, 2017; Terra, 2011). Nesta pesquisa olhamos para o público interno da base operacional da indústria. Ao se apropriar desses dispositivos comunicacionais de forma intensa com a proliferação de smartphones, queremos conhecer como se dá a interação desse público que tem restrições do uso de celulares em linhas de produção por motivos de segurança no trabalho.

Ao escolher esses trabalhadores como objeto deste estudo qualitativo, selecionamos prioritariamente operários nascidos a partir da década de 1980 , os chamados millenials ou nativos digitais ${ }^{2}$, por terem vivenciado a internet na juventude. Essa geração corresponde atualmente a mais de $70 \%$ do mercado formal de trabalho 3 . Para o público em questão, a comunicação digital tem uma importância natural e crítica para a satisfação, conforme revelado nas entrevistas realizadas para a primeira etapa desta pesquisa ${ }^{4}$.

Antes de adentrarmos na correlação da comunicação com a satisfação no trabalho, é importante destacar que a revisão bibliográfica revelou falta de consenso conceitual sobre a satisfação ou insatisfação no trabalho entre os pesquisadores

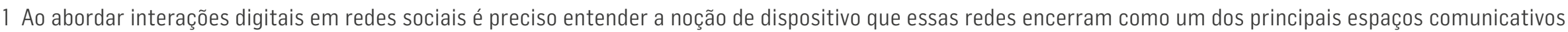

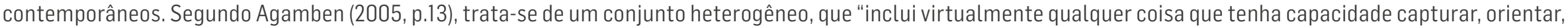

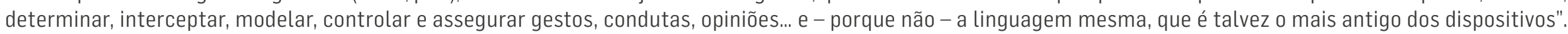
Já Braga (2012) denomina como dispositivo interacional todo e qualquer espaço de mediação da interação.

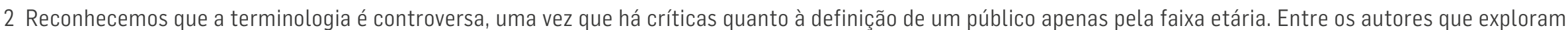

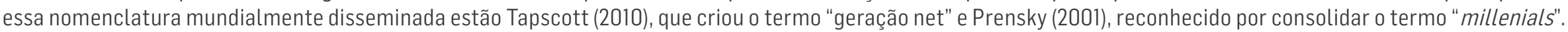

3 Fonte: IBGE, 2016. Disponível em https://goo.gl/RZWD9Y. Acesso em 3 set. 2017.

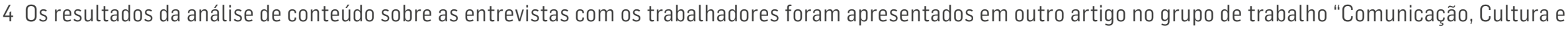
Sociedade" do IX Encontro de Pesquisa em Comunicação (Enpecom 2017), sob o título: "Interações digitais e satisfação laboral na comunicação interna".
} 
que mapeiam a trajetória e a terminologia (Alfaiate; Santos, 2016; Hora; Ribas Júnior; Souza, 2018; Marquese; Moreno, 2005; Rente, 2016; Robbins, 2005; Silva Junior, 2001).

Mesmo considerando que diferentes perspectivas contribuem para o conhecimento, destacamos aqui apenas um denominador comum entre as teorias encontradas: a de que a satisfação é vista como um sentimento gerado a partir de crenças e valores do trabalhador em relação a seu ambiente profissional. E no caso do objeto em estudo, a partir das conversas com os sujeitos investigados, foi encontrado um elevado índice de satisfação laboral. Entre os 23 participantes de entrevistas semiestruturadas, $61 \%$ se consideram satisfeitos com o trabalho em geral na indústria analisada ${ }^{5}$ e $39 \%$ muito satisfeitos . $^{6}$

A verificação das pegadas digitais desses indivíduos nas redes sociais virtuais foi importante para cruzar os dados com os depoimentos prestados para esta pesquisa realizada no mestrado em Comunicação da Universidade Federal do Paraná (UFPR). Neste artigo apresentamos possibilidades mais relevantes entre as descritas na dissertação que procurou saber como as interações digitais atravessam o cotidiano recortado e observado pelas evidências de (in)satisfação. E em que medida contribuem para a satisfação com o trabalho - por ter sido este o sentimento mais revelado nos sintagmas encontrados.

Por exemplo, a interação mobilizada pela expectativa social de senso de pertencimento e de colaboração que remete à satisfação laboral se replica no contexto digital. Autores que vivenciam profissionalmente nas organizações os desafios da comunicação interna destacam que "o sentido de pertencimento se coloca como uma resposta à necessidade do ser humano de afiliação, de identificação e relacionamento" (Soares; Del Gáudio, 2017, p.29).

Pensar a comunicação organizacional como interação permite ressaltar sua dimensão social prática, no âmbito da experiência dos sujeitos que se influenciam e se transformam mutuamente na produção de sentidos. Por isso, Kunsch (2009) aborda a comunicação organizacional pelo paradigma interpretativo. Na mesma linha, Taylor (2000) e Casali (2009) explicam as interações pelo princípio de coorientação ${ }^{7}$ defendido pela Escola de Montreal, identificando pontos em comum que remetem a significados simbólicos e subsimbólicos que permeiam a cultura organizacional, sendo perceptíveis pela análise textoconversação $0^{8}$.

Nessa perspectiva, como a finalidade da conversação é sustentar a interação e o texto é resultado de uma interpretação negociada coletivamente, as interações passam a configurar o espaço onde a empresa se constrói ou se destrói, sendo que 0 público interno exerce um dos papéis mais críticos, por vivenciar a realidade organizacional e por representar a organização também externamente. Tal condição confere aos trabalhadores da organização mais autoridade natural no ciberespaço para defesa ou crítica da instituição que representam.

Assim a internet torna-se um laboratório social natural no qual as mídias sociais são artefatos culturais (Hine, 2004). E no caso investigado, as redes sociais funcionam como extensão do ambiente da comunicação interna, em que exploramos os fundamentos da etnografia virtual para coletar os dados e interpretá-los com base no método de análise de conteúdo de Bardin (2016).

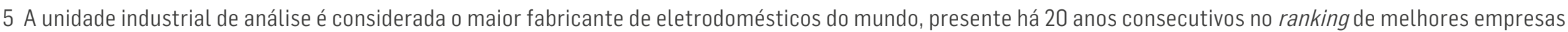
para se trabalhar pelo guia Great Place to Work.

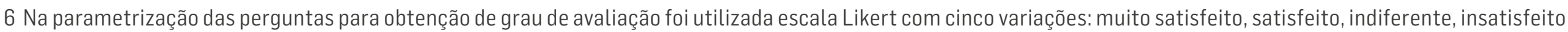
e muito insatisfeito.

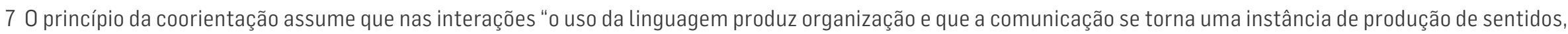
agenciamento e posicionamento social, ao mesmo tempo em que atua sobre o mundo material" (Casali, 2007, p.8).

8 A análise texto-conversação é um princípio metodológico da Escola de Montreal aplicado neste estudo. 


\section{METODOLOGIA E RESULTADOS}

\section{Etnografia virtual em página coletiva do Facebook}

Entre as discussões acerca dos métodos de pesquisa para internet, Fragoso, Recuero e Amaral (2011) defendem a ideia da rede como artefato cultural que traduz a existência de uma multiplicidade de significados e contextos, constituindo o elemento criador da cultura de conexão (Jenkins, 2009). Trata-se de uma abordagem ainda em franco desenvolvimento, como uma adaptação do método etnográfico de base antropológica para os ambientes on-line.

Nesta pesquisa analisamos uma página encontrada no Facebook, criada de forma independente pelos empregados da base fabril, a qual configura uma comunidade virtual (Recuero, 2009). Na verdade, foram encontradas duas páginas não oficiais em nome da organização analisada com esse tipo de acesso público. Consideramos como mais profícua fonte de coleta a que apresenta maior impacto e repercussão, com aproximadamente 15 mil visualizações e mais de 1.300 curtidas, além de contar com atualizações mensais frequentes. A escolha também se mostrou adequada pelo fato de terem sido encontrados vários posts de oito dos 13 entrevistados que se manifestaram interagentes do Facebook entre os sujeitos pesquisados.

Neste estudo, a opção por um acompanhamento sistemático silencioso ocorre basicamente por dois motivos: checagem se a lógica discursiva relatada nas entrevistas se refletia de forma coerente na rede, como uma possível confirmação ou não da satisfação laboral fortemente manifestada, e procurar não intervir na realidade encontrada, buscando-se maior isenção na investigação. Compreendendo então as mídias sociais como um dos dispositivos interacionais que favorecem um processo comunicativo em tese mais espontâneo e livre, o objetivo nesta etapa foi descobrir quais categorias caracterizam as interações no espaço em recorte. Para Braga (2012, p. 32), "os códigos são a produção resultante das interações"; para Taylor (2000, p.238), o texto é o discurso codificado.

A apreciação sistemática foi realizada ao longo de três meses, de junho a agosto de 2017, abrangendo inicialmente 578 posts. Verificamos que a maioria das postagens é imagética, com muitas fotos pessoais e/ou de equipes de trabalho (porém sem constar arquivos de vídeo e áudio) e pouquíssimo texto, tanto nos posts, quantos nos comentários, conforme registrado no Quadro 1.

Quadro 1: Volume de postagens por mês no Facebook

\begin{tabular}{|c|c|c|}
\hline \multicolumn{2}{|c|}{ Quantidade de publicações } & Agosto \\
\hline Junho & Julho & 257posts \\
\hline 182 posts & Publicadosts por 64 pessoas \\
\hline Publicados por 72 pessoas & & $\begin{array}{c}\text { Publicados por } \\
57 \text { pessoas }\end{array}$ \\
\hline $\begin{array}{c}\text { Obs.: Ao longo do período observado só foi } \\
\text { encontrado, nesse mês, um post de um } \\
\text { funcionário que começou como terceirizado } \\
\text { e depois não foi efetivado, revelando } \\
\text { franca insatisfação com a empresa. }\end{array}$ & $\begin{array}{c}\text { Obs.: Nesse mês aconteceu a Semana de } \\
\text { Prevenção de Acidentes com Máquinas } \\
\text { (Sipamaq), o que impulsionou o nível de } \\
\text { publicações, principalmente em equipe. }\end{array}$ & Obs.: nada consta. \\
\hline
\end{tabular}

Fonte: Elaborado pelas autoras. 
A primeira percepção dessas postagens é que os interagentes são majoritariamente profissionais da base produtiva, ou seja, trata-se de um espaço visivelmente ocupado por trabalhadores da linha de produção. 0 que isto significa? Que a mesma departamentalização típica do mundo organizacional físico ou off-line se reflete na rede on-line (Recuero, 2009, 2014).

Observamos também o fato de a maioria das postagens remeter à satisfação laboral, bem como a interação com o dispositivo como forma de autoexpressão pessoal ou de orgulho de pertencer a um grupo. Os resultados apresentados e analisados na sequência fazem parte do corpus composto pelos 71 posts, por corresponderem a um olhar de lupa representativo do volume inicial de 578 posts observados, excluindo-se os check-ins e saudações triviais. A decisão de descartar esses posts parte de um critério essencial para análise de base etnográfica na internet. Segundo vários autores (Hine, 2004; Primo, 2007; Recuero, 2009; Rheingold, 1993), no empreendimento analítico é preciso entender em qual contexto sociocultural as interações digitais estão inseridas.

Ao todo identificamos quatro categorias principais resultantes dos sintagmas expressos por imagens (selfies e emoticons) e textos, conforme mostra o Quadro 2. As categorias foram definidas a posterioripor afinidade temática (Bardin, 2016). Em alguns casos um post foi enquadrado em mais de uma categoria pela possibilidade polissêmica. Para fins analíticos, as categorias identificadas na sequência basearam-se no princípio de coorientação da Escola de Montreal ${ }^{9}$.

Quadro 2: Categorias relacionadas à satisfação e à insatisfação laboral no Facebook

\begin{tabular}{|c|c|c|c|}
\hline \multicolumn{3}{|c|}{ Unidades de contexto observadas nos 71 posts analisados } \\
\hline \multicolumn{2}{|c|}{ Aspectos possíveis de serem relacionados à satisfação } & $\begin{array}{c}\text { Aspectos possíveis de serem } \\
\text { relacionados à insatisfação }\end{array}$ \\
\hline $\begin{array}{c}\text { Expressão pessoal - } \\
\text { fruição }\end{array}$ & $\begin{array}{c}\text { Expressão coletiva - } \\
\text { colaboração e integração }\end{array}$ & Motivação inspiracional & Cansaço ou frustração \\
\hline 44 posts & 38 posts & 19 posts & 4 posts \\
\hline $62 \%$ & $53,5 \%$ & $27 \%$ & $5,6 \%$ \\
\hline
\end{tabular}

Fonte: Elaborado pelas autoras.

Além de buscar o que há em comum, procuramos atentar também para as diferenças e ausências do que foi observado, como orienta Bardin (2016). No geral, vários aspectos chamam atenção e inspiram as reflexões a seguir.

Destacamos o fato de só constarem quatro manifestações sobre cansaço ou ritmo de trabalho exaustivo em 71registros. Mas, como pesquisa qualitativa, as diferenças reveladas em abordagem minoritária não podem ser desconsideradas. Posts como esse são raros, mas constam na página. Inferimos que, normalmente, as pessoas não se sentem à vontade para publicar conteúdo desanimador, pois são visualizados mais posts de incentivo, como "força, bora e vamo que vamo" ou ainda de conquistas e superações, momentos alegres e comemorações. Com base na Teoria da Espiral do Silêncio (Noelle-Neumann, 1995), inferimos que quem está infeliz, insatisfeito ou frustrado, normalmente prefere não se expor por perceber-se como parte de uma minoria.

O Facebook é mais usado pelos trabalhadores da base da empresa como espaço de autoexpressão (expressão identitária), fruição (prazer e relaxamento, curtição com colegas), motivação (reflexão com frases edificantes inspiradoras) e integração (notadamente marcada pelo orgulho de pertencer ao grupo de trabalho - expressão identitária coletiva). Especificamente

9 A análise texto-conversão e a coorientação são princípios metodológicos da Escola de Montreal. 
sobre a evidência de autoexpressão, Recuero (2009, p.25-26) confirma que quando se trabalha com redes sociais na internet os atores se constituem de maneira diferenciada, explorando seu alter ego no ciberespaço: "Trabalha-se com representações [...] são lugares de fala construídos pelos atores de forma a expressar elementos de sua personalidade ou individualidade [...] uma expressão do self". No caso em estudo, fica claro que os posts identitários e motivacionais traduzem uma busca de sentido e propósito maior para o trabalho.

É perceptível também o traço proeminente da interação com o dispositivo como espaço. E não na interação entre os autores dos posts em si, o que caracterizaria um processo dialógico social (Primo; Oliveira; Nascimento, 2008; Recuero, 2009). Tal inferência decorre do fato de a comunicação entre as pessoas não ter ficado suficientemente evidenciada na comunidade virtual em tela, pois há baixa interação entre os participantes. Isto se verifica no nível de curtidas por post que não apresenta regularidade e pode ser considerado pequeno diante do número total de curtidas na página no período analisado (com variação mínima de 0 - a absoluta maioria -, ao máximo de 328 curtidas - número encontrado em apenas um post), sendo igualmente baixo o nível de comentários no período (menos de 50, equivalendo a menos de $10 \%$ do número total inicial de posts estudados). As postagens em geral remetem a poucas interações mútuas e parecem refletir o senso de comunidade, espelhando claramente a relação laboral off-line, o que Recuero (2009) atribui à formação de laços associativos, tipicamente encontrados nas redes sociais digitais profissionais, conforme o Quadro 3.

Quadro 3: Tipos de laço e tipos de interação no Facebook

\begin{tabular}{|c|c|c|}
\hline Tipo de laço & Tipo de interação & Exemplos \\
\hline Associativo & $\begin{array}{c}\text { Reativa } \\
\text { Curtidas de posts dos } \\
\text { colegas de trabalho. } \\
\text { (interação que permite a escolha } \\
\text { de caminhos pré-definidos) } \\
\text { Dostagens com narrativas de si } \\
\text { próprio ou do grupo a que pertence } \\
\text { - selfies na maioria dos casos. }\end{array}$ \\
\hline Dialógico & $\begin{array}{c}\text { Mútua } \\
\text { (interação que permite a livre } \\
\text { troca comunicacional) }\end{array}$ & $\begin{array}{c}\text { Compartilhamentos e comentários } \\
\text { sobre as postagens dos colegas. }\end{array}$ \\
\hline
\end{tabular}

Fonte: Adaptado de Recuero, 2009.

Para a autora, as comunidades associativas são baseadas na identificação dos atores com um elemento comum, como um objeto, lugar ou ideia que formam o vínculo construído. "Elas possuem uma estrutura bastante diversificada, com poucas conexões, atores mais isolados. [...] A interação mútua pode aparecer, mas predomina a reativa. A dinâmica mais comum é de agregação, cooperação e pouco desgaste" (Recuero, 2009, p.162). Tais características coincidem com o objeto em estudo, com destaque para o vínculo de pertencimento que não precisa de interações mútuas para ser mantido.

Interessante observar que, dentro das características mais encontradas nas comunidades associativas, dependendo do contexto em que as interações ocorrem, o sinal de "curtir" tem uma conotação dialógica de concordância, de validação do conteúdo. Mas Recuero (2014) alerta que a curtida nesse tipo de comunidade virtual pode ser apenas um indício de apropriação no sentido de tomar parte, como um investimento mínimo relacional, que não chega a estabelecer um diálogo se não tiver avanço em algum tipo de ação. Por analisar dentro dessa ótica, no Quadro 3 as poucas curtidas foram classificadas como interações reativas.

O baixo número de interações comentadas no geral também revela que a maioria aparenta interagir na rede como fruto do laço associativo e modo de autoexpressão, utilizando o Facebook como metáfora de diário, sem expectativa de resposta, sem 
aplauso ou feedback, confirmando o relato de apropriação identitária por parte de alguns entrevistados. Nesse sentido, a rede social como espaço circular não favorece o dialogismo. Tal ocorrência corrobora uma tendência identificada na internet, em que as pessoas utilizam a rede para "ampliar a autoexpressão ou falar para si próprios" (Castells, 2015, p.113).

Neste trabalho, reconhecemos a organização como um sistema oriundo da dinâmica comunicativa em constante transformação. "Sobrevive em virtude do embate entre ordem, desordem, contentamento, descontentamento, aceitação, não aceitação, que conformam o espaço interno" (Oliveira; Alencar, 2013, p.215). Nesse processo, o conflito faz parte das relações organizacionais, existindo uma tensão natural muitas vezes marcada por interesses divergentes. Mas também há sempre espaço para algum nível de satisfação, o que não pode ser desprezado, conforme encontrado claramente neste estudo. Acreditamos que as organizações vivam nesse equilíbrio tênue e aquelas que sobrevivem certamente são as que passam a maior parte do tempo com as pessoas interagindo e expressando algum grau de satisfação laboral que sobrepuja à insatisfação.

\section{CONSIDERAÇÕES FINAIS}

Esta investigação avaliou as interações dos profissionais da base produtiva nas mídias sociais no contexto da comunicação interna informal e sua correlação com a satisfação laboral. Entendemos que a compreensão deste fenômeno representa oportunidades e desafios para a comunicação organizacional.

A pesquisa completa articulou as matrizes do Interacionismo Simbólico e da Escola de Montreal para demonstrar no caso em estudo em que medida a comunicação interna informal nas mídias sociais revela a satisfação no trabalho. Satisfação que, por sua vez, é um valor considerado essencial para os profissionais entrevistados. Os trabalhadores da amostra são jovens e parecem mais dispostos a dar visibilidade à sua experiência laboral na rede como parte da vida cotidiana narrada na internet.

Este artigo analisa os resultados com base nos fundamentos da etnografia virtual para identificar como as interações digitais refletem a satisfação laboral encontrada. A análise de conteúdo aplicada com metodologia híbrida (quanti/quali), recomendada por Bardin (2016), permitiu mais subsídios para a interpretação dos achados.

Consideramos que os dados obtidos corroboram os princípios da Escola de Montreal de que a comunicação organizacional não é incidental. Empresas são feitas de pessoas e pessoas produzem sentido por meio de suas interações. Portanto, a descoberta da organização se revela pelas narrativas, demonstrando coerência discursiva tanto nas entrevistas, quanto nas postagens do Facebook.

A maior parte das postagens é de foto individual ou coletiva que expressa a versão identitária desejada. Numa espécie de diário virtual, mais parece valer a marcação de presença no dispositivo do que a própria interação com os colegas. A inferência se baseia também na observação do baixo número de curtidas e compartilhamentos na página coletiva em recorte que aponta para um tipo de laço social associativo reativo no dispositivo.

Mesmo sendo criada de forma independente pelos empregados, a comunidade no Facebook espelha a mesma departamentalização encontrada nas organizações, que não apresenta a participação de gestores ou de trabalhadores administrativos em geral.

Os posts avaliados acabam indicando uma visível relação entre as interações digitais e a satisfação no trabalho, confirmando o que foi apreendido nas entrevistas. 0 aspecto colaborativo se destaca. 0 fato de repercutir na rede os bons resultados obtidos com a colaboração coletiva, ou mesmo de aparecer como colegas unidos, gera mais satisfação pessoal no sentido 
de pertencimento grupal. Oliveira (2008, p.104) explica essa importância do senso de pertencer: "O processo de inserção é 0 que permite que as pessoas se posicionem no mundo. Assim, acabam por indicar às demais como fazê-lo".

A autoexpressão é outro aspecto que desponta. Soares e Del Gáudio (2017) destacam três necessidades básicas dos empregados: afiliação, autoestima e identificação. E na amostra investigada, o alter ego (o outro eu) dos entrevistados na rede valida a assertiva: o fato de poder criar uma persona virtual que luta, não desiste, que é grata pelo que tem, dá força para seguir em frente. As imagens e frases edificantes encontradas denotam que há uma busca por significado e propósito no trabalho para além da tarefa.

Os enunciados apresentados em ambos os espaços analisados (nas entrevistas e na internet) denotam que ora as pessoas são agentes construtores da organização pelos seus atos de fala e ora são resultantes da própria narrativa corporativa estabelecida por conta da cultura organizacional dominante, fruto do processo de coorientação. Daí o discurso hegemônico, a superfície percebida da organização segundo Taylor e Every (2000), perceptível no recorte investigado que aponta para a satisfação laboral, num ambiente que notadamente (pelos depoimentos e materiais publicados no site da empresa, além de outdoors espalhados pela fábrica) promovem o respeito mútuo e a colaboração.

Outra questão de fundo que se impõe na pesquisa remete à importância da ação coletiva como resultado de ações individuais alinhadas ao mesmo propósito - o que também demonstra a influência das interações sobre o senso de pertencimento explícito para a percepção de satisfação no trabalho. E, finalmente, que os indivíduos não abrem mão de demonstrar suas personas, em forma de self(idealizadas ou não, teatralizadas ou não) - agora, mais do que nunca, alavancadas pelas mídias sociais.

Conclui-se que os trabalhadores da base estão ávidos por interagir e ampliar seu poder de voz em qualquer meio - o digital seria mais uma fronteira a ser ocupada. As interações digitais ampliam o empoderamento dos empregados e as que ocorrem na informalidade das redes sociais potencializam cada vez mais sua autonomia, ativismo e, consequentemente, a influência nos destinos da organização.

\section{REFERÊNCIAS}

AGAMBEN, Giorgio.0 que é um dispositivo. Outra Travessia, Florianópolis, n.5, p.9-16, 2005. Disponível em: https://bit. ly/20F240s. Acesso em: 15 nov. 2017.

ALFAIATE, Helena Sofia; SANTOS, Joana Vieira dos. Liderança ética e marketing interno: análise das repercussões na satisfação e empenhamento de profissionais ativos. Revista E-Psi, [s.l.], v.2, n.6, p.26-44, 2016. Disponível em: https://bit.ly/2tCMNIE. Acesso em 20 jan. 2017.

BARDIN, Laurence. Análise de conteúdo. São Paulo: Edições 70, 2016.

BARICHELLO, Eugenia M. R.; SCHEID, Daiane. Visibilidade midiática organizacional: apontamentos sobre a presença da Universidade Federal de Santa Maria no Facebook. Revista Internacional de Relaciones Públicas, Málaga, n.13, v.VII, p.123-140, 2017. doi:10.5783/RIRP-13-2017-08-123-140.

BRAGA, José Luiz. Interação como contexto da comunicação. Matrizes, São Paulo, ano6, n.1, p.25-41, jul./dez. 2012. 
BUENO, Wilson da Costa.Comunicação interna e liderança aberta: os desafios de incorporar a geração Y e as mídias sociais. Organicom, São Paulo, v.10, n.19, p.60-71, 2013. doi: 10.11606/issn.2238-2593.organicom.2013.139192.

BUENO, Wilson da Costa (org.). Estratégias de comunicação nas mídias sociais. Barueri: Manole, 2015.

CARRAMENHA, Bruno. Tendências na gestão da comunicação com os empregados. In: MANZI, Viviane; CARRAMENHA, Bruno (org.). Comunicação com líderes e empregados: artigos de alunos e convidadas da Pós-Graduação em Comunicação Corporativa e Relações Públicas da Faculdade Cásper Líbero. Jundiaí: In House, 2016. p.125-133. Disponível em: http://bit.ly/2xl5BY2. Acesso em: 8 jul. 2017.

CARVALHO, Ana Paula P.; FORT, Mônica C. Conexões virtuais e desconexões presenciais: a comunicação via WhatsApp em ambientes corporativos. Comunicação e Inovação, São Caetano do Sul, v.18, n.36, 2017. Disponível em: https://bit.ly/2KhjHPM. Acesso em: 15 mar. 2017.

CASALI, Adriana M. Proposta de um Modelo de Análise do Processo de Comunicação Organizacional a partir das Proposições da Escola de Montreal. In: ENCONTRO DA ASSOCIAÇÃO NACIONAL DE PÓS-GRADUAÇÃO E PESQUISA EM ADMINISTRAÇÃO, 31., 2007, Rio de Janeiro. Anais [...]. Maringá: Anpad, 2007. Disponível em: https://bit.ly/37vL2tH. Acesso em: 25 out. 2016.

CASALI, Adriana M. Um modelo do processo de comunicação organizacional na Perspectiva da Escola de Montreal. In: KUNSCH, Margarida M. K. (org.). Comunicação organizacional: histórico, fundamentos e processos. São Paulo: Saraiva, 2009. p.107-134.

CASTELLS, Manuel. O poder da comunicação. São Paulo: Paz e Terra, 2015.

CORRÊA, Elisabeth S. A comunicação digital nas organizações: tendências e transformações. Organicom, São Paulo, v.6, n.10-11, p.161-167, 2009. Disponível em: https://bit.ly/2zJFp9r. Acesso em: 1 jul. 2016.

DI FELICE, Massimo. As formas digitais do social e os novos dinamismos da sociabilidade contemporânea. In: KUNSCH, Margarida M. Krohling; KUNSCH, Waldemar Luiz. (org.). Relações públicas comunitárias. a comunicação em uma perspectiva dialógica e transformadora. São Paulo: Summus, 2007. V.1, p.29-44. Disponível em: https://bit.ly/2tEo8wU. Acesso em: 5. jul. 2016.

DREYER, Bianca M. Relações Públicas na contemporaneidade. São Paulo: Summus, 2017.

FRAGOSO, Suely; RECUERO, Raquel; AMARAL, Adriana. Métodos de pesquisa para internet. Porto Alegre: Sulina, 2011.

HINE, Christine. Etnografía virtual. Barcelona: Editorial UOC, 2004.

HORA, Gabriela Pereira Rangel; RIBAS JÚNIOR, Rodolfo; SOUZA, Marcos Aguiar de. Estado da arte das medidas em satisfação no trabalho: uma revisão sistemática. Trends in Psychology, Ribeirão Preto, v.26, n.2, p.971-986, jun. 2018. Disponível em: https://bit.ly/2tBNStP. Acesso em: 21 jun. 2018.

JENKINS, Henry. Cultura da convergência. São Paulo: Aleph, 2009.

KUNSCH, Margarida M. K. (org.). Comunicação organizacional: histórico, fundamentos e processos. São Paulo: Saraiva, 2009. 
LUPIANHES, Karen. A influência das redes sociais na comunicação e no ambiente interno de trabalho. Refas: revista Fatec Zona Sul, São Paulo, v.3, n.2, p.1-22, 2017. Disponível em: https://bit.ly/2Kl5mVO. Acesso em: 8 abr. 2017.

MARCHIORI, Marlene. Comunicación Interna: una visión más amplia en el contexto de las organizaciones. Ciências de la Información, Havana, v.42, n.2, p.49-54, maio/ago. 2011. Disponível em: https://bit.ly/2L7VfD9. Acesso em: 18 jun. 2016.

MARQUESE, Elaine C.; MORENO, Claudia R. C. Satisfação no trabalho - uma breve revisão. Revista Brasileira de Saúde Ocupacional, São Paulo, v.30, n.112, p.69-79, 2005. Disponível em: https://bit.ly/2luCYvk. Acesso em: 17 set. 2016.

NOELLE-NEUMANN, Elisabeth. La espiral de silencio. Opinion publica: nuestra piel social. Barcelona: Paidós, 1995.

OLIVEIRA, Ivone de Lourdes. Constituição do campo da comunicação no contexto organizacional: interfaces e construção de sentido. In: JESUS, Eduardo de; SALOMÃO, Mozahir (org.). Interações plurais: a comunicação e o contemporâneo. São Paulo: Annablume, 2008. p.91-108.

OLIVEIRA, Ivone de Lourdes; ALENCAR, Terezinha G. R. A dinâmica comunicativa no ambiente interno das organizações: interrelação da comunicação formal com a comunicação informal. Organicom, São Paulo, ano10, n.19, p. 209-219, 2013. doi:10.11606/issn.2238-2593.organicom.2013.139204.

PESQUISA Mensal de Emprego. Instituto Brasileiro de Geografia e Estatística, Rio de Janeiro, 2016. Disponível em: https:// bit.ly/2OFTaQG. Acesso em: 3 set. 2017.

PRENSKY, Marc. Digital Natives, Digital Immigrants. On the Horizon, [Bradford], v.9, n.5, 2001. Disponível em: https://bit. ly/2R9rnd4. Acesso em: 7 abr. 2016.

PRIMO, Alex. Interação mediada por computador. comunicação, cibercultura, cognição. Porto Alegre: Sulina, 2007.

PRIMO, Alex; OLIVEIRA, Ana Claudia de; NASCIMENTO, Geraldo Carlos do; RONSINI, Veneza Mayora (org.). Comunicação e interações. Porto Alegre: Sulina, 2008.

RECUERO, Raquel. Redes sociais na internet. Porto Alegre: Sulina, 2009.

RECUERO, Raquel. Curtir, compartilhar, comentar: trabalho de face, conversação e redes sociais no Facebook. Verso e Reverso, São Leopoldo, v.XXVIII, n.68, p.114-124, 2014.

RENTE, Ana I. G. Estudo da relação entre a confiança grupal e a satisfação dos membros numa perspectiva longitudinal e dinâmica. 2016. 41f. Dissertação (Mestrado em Psicologia das Organizações e do Trabalho) - Faculdade de Psicologia e de Ciências da Educação, Universidade de Coimbra, Coimbra, 2016. Disponível em: https://bit.ly/2tBFVoE. Acesso em: 26 dez. 2016.

RHEINGOLD, Howard. The virtual community. Cambridge: The MIT Press, 1993. Disponível em: https://bit.ly/35Z3oRZ. Acesso em: 15 nov. 2017.

ROBBINS, Stephen P. Comportamento organizacional. São Paulo: Prentice Hall, 2005. 
SILVA JUNIOR, Nelson A. Satisfação no trabalho: um estudo entre os funcionários dos hotéis de João Pessoa. PsicoUSF, Itatiba, v.6, n.1, p.47-57, 2001. Disponível em: https://bit.ly/2KkDIln. Acesso em: 14 dez. 2016.

SOARES, Paulo H. L.; DEL GÁUDIO, Rozália. Sem megafone, com smartphone: práticas, desafios e dilemas da comunicação com os empregados. São Paulo: Aberje, 2017.

TAPSCOTT, Don. A hora da geração digital: como os jovens que cresceram usando a internet estão mudando tudo, das empresas aos governos. Rio de Janeiro: Agir Negócios, 2010.

TAYLOR, James R.; EVERY, Elizabeth J. V. The Emergent Organization: Communication as its site and surface. New Jersey: Lawrence Erlbaum Associates, 2000.

TERRA, Carolina F. Usuário-mídia: a relação entre a comunicação organizacional e o conteúdo gerado pelo internauta nas mídias sociais. 2011. 207f. Tese (Doutorado em Comunicação) - Escola de Comunicações e Artes, Universidade de São Paulo, São Paulo, 2011. Disponível em: https://bit.ly/2tuFdtX. Acesso em: 20 jun. 2016.

TERRA, Carolina F. Mídias sociais e público interno: o uso das redes sociais online de maneira informal. In: CONGRESSO BRASILEIRO DE CIÊNCIAS DA COMUNICAÇÃO, 38., 2015, Rio de Janeiro. Anais [...]. São Paulo: Intercom, 2015. Disponível em: https://bit.ly/2K8DOnq. Acesso em: 6 set. 2017.

Artigo recebido em 28.05.2019 e aprovado em 21.11.2019. 